\title{
Update on the role of candesartan in the optimal management of hypertension and cardiovascular risk reduction
}

This article was published in the following Dove Press journal:

Integrated Blood Pressure Control

26 May 2010

Number of times this article has been viewed

\author{
Ikechi G Okpechi \\ Brian L Rayner \\ Department of Medicine, Division \\ of Nephrology and Hypertension, \\ Groote Schuur Hospital and University \\ of Cape Town, Observatory, Cape \\ Town 7925, South Africa
}

\begin{abstract}
Hypertension is the most prevalent cardiovascular disease of adults and is a major risk factor for cardiovascular (CV) and cerebrovascular morbidity and mortality worldwide. Treatment of hypertension leads to reduction of CV morbidity and mortality through blood pressure reduction. The role of renin-angiotensin-aldosterone system (RAAS) in the pathophysiology of hypertension is mainly through generation of potent vasoconstrictor angiotensin II, stimulation of aldosterone secretion, and increase in sympathetic activation. Angiotensin II receptor blockers such as candesartan, a long-acting agent, alter this system by blocking the activation of angiotensin I receptors. Several important clinical trials have tested the efficacy of candesartan with placebo, antihypertensive agents, or other agents that block the RAAS for the control of hypertension and reduction of key CV risk factors such as microalbuminuria, heart failure, retinopathy, and carotid intima medial thickness. Candesartan has been shown to be a welltolerated and effective antihypertensive agent with positive metabolic characteristics and additional benefits on $\mathrm{CV}$ and cerebrovascular outcomes. The aim of this review is to discuss the pharmacology, efficacy, and safety of candesartan, with an overview of key hypertension and $\mathrm{CV}$ studies involving candesartan.
\end{abstract}

Keywords: ACE inhibitor, ARB, blood pressure, treatment, heart

\section{Introduction to hypertension management and $\mathrm{CV}$ risk reduction}

Hypertension is the most prevalent cardiovascular disease (CVD) of adults and is a major risk factor for both cardiovascular (CV) and cerebrovascular morbidity and mortality worldwide. ${ }^{1}$ Although the results of several cross-sectional or cohort epidemiological studies have shown that the prevalence of hypertension varies significantly, ${ }^{2-7}$ essential hypertension is estimated to affect $30 \%$ of adults ${ }^{8,9}$ and to account for up to $30 \%$ of all deaths. ${ }^{1}$ The relationship between blood pressure (BP) and $\mathrm{CV}$ risk is continuous such that every $20 \mathrm{mmHg}$ increase in systolic BP (SBP) or $10 \mathrm{mmHg}$ increase in diastolic BP (DBP) doubles the risk of CVD. ${ }^{10}$ The main objective of hypertension treatment is to reduce CV morbidity and mortality by reducing BP. ${ }^{11}$ Inameta-analysis of placebo-controlled hypertension studies, for every $12 / 6 \mathrm{mmHg}$ reduction in $\mathrm{BP}$, there was a $35 \%-40 \%$ reduction in stroke, $20 \%-25 \%$ reduction in myocardial infarction, and $>50 \%$ in heart failure (HF) and prevention of CVD-related death rates. ${ }^{11}$

An estimated one-third of all hypertensive patients still remain untreated despite the level of awareness of hypertension worldwide, and over half of those treated have uncontrolled hypertension. ${ }^{12}$ The increased mortality and morbidity associated with uncon- 
trolled hypertension results in a substantial economic burden. Antihypertensives that are effective and well tolerated are important for persistence with therapy and hence control of BP.

The role of renin-angiotensin-aldosterone system (RAAS) in the pathophysiology of hypertension is pivotal mainly through the generation of powerful vasoconstrictor angiotensin II, which significantly contributes to hypertension through vasoconstriction, stimulation of aldosterone secretion, and increase in sympathetic activation. Angiotensin II receptor blockers (ARBs), therefore, modulate the RAAS by blocking the activation of angiotensin I (AT1) receptors, resulting in vasodilatation, reduced sympathetic activation, and reduced salt and water retention. ARBs also block angiotensin II production irrespective of whether it is generated by AT1 through angiotensin converting enzyme (ACE) pathway or through alternative pathways such as chymase. This article reviews the pharmacology, efficacy, and safety of candesartan (an ARB), with an overview of key hypertension and CV studies involving candesartan.

\section{Pharmacology of candesartan}

After oral administration, candesartan cilexetil is rapidly converted to candesartan (an active drug) by hydrolysis in the gastrointestinal tract, with an average absolute bioavailability of candesartan of approximately $40 \%$. Candesartan is highly bound to plasma protein $(>99 \%) .{ }^{13}$ The serum concentration (AUC) of candesartan is not significantly affected by food intake, and $\mathrm{T}_{\text {max }}$ is reached within 3-5 hours after oral administration. ${ }^{13}$ The AUC of candesartan has shown dose linearity with increasing doses in the therapeutic dose range. ${ }^{14}$ Elimination of the drug is largely via urine and bile in an unchanged form, and only an insignificant amount of the drug is inactivated by hepatic metabolism. an oral dose of candesartan, about $20 \%-30 \%$ is excreted in urine and $60 \%-70 \%$ is excreted in feces. The apparent volume of distribution of candesartan is $0.1 \mathrm{~L} / \mathrm{kg}$. The terminal half-life of candesartan is 5-9 hours, and no significant accumulation after multiple doses was observed (plasma concentrations $+3 \%$ to $+17 \%$ ). ${ }^{14}$ Total plasma clearance of candesartan is about $0.37 \mathrm{~mL} / \mathrm{min} / \mathrm{kg}$, with a renal clearance of about $0.19 \mathrm{~mL} / \mathrm{min} / \mathrm{kg}$. Candesartan has high selectivity for AT1 receptors, with tight binding to and slow dissociation from the receptor. ${ }^{15}$ In displacement studies using rabbit aortic membranes, candesartan's affinity for the AT1 receptor was found to be 80 times higher than that of losartan. ${ }^{16}$ Due to candesartan's tight binding to and slow dissociation from the AT1 receptors, candesartan cilexetil provides a dose-related and long-lasting antihypertensive effect. ${ }^{15,17}$

\section{Candesartan: antihypertensive efficacy}

The reduction of BP alone does not eliminate the increased risk of arterial hypertension, and the agents that block the RAAS theoretically offer additional benefits other than reduction of BP, but this has been difficult to prove in practice. Candesartan has been used in several key clinical trials of hypertension to determine its efficacy, tolerability, and safety (Table 1).

\section{BP-lowering efficacy: candesartan versus placebo studies}

Reif et al ${ }^{18}$ evaluated the dose-related efficacy, tolerability, and safety of candesartan cilexetil in 365 adult patients with hypertension; all doses of candesartan cilexetil $(2,4,8,16$, or $32 \mathrm{mg}$ once daily for 8 weeks) reduced trough sitting DBP $(-7.1,-8.4,-8.7,-7.8$, and $-10.2 \mathrm{mmHg}$, respectively) and SBP $(-8.9,-10.5,-9.9,-10.7$, and $-12.6 \mathrm{mmHg}$, respectively) significantly compared with placebo $(P<0.005)$. A significant $(P<0.0001)$ dose response was evident, with greater decreases in $\mathrm{BP}$ at higher doses. In a meta-analysis that reviewed the antihypertensive activity of several ARBs, ${ }^{19}$ candesartan showed significant clinical and 24-hour SBP and DBP reductions compared with placebo. Similarly, in the Trial of Preventing Hypertension (TROPHY) ${ }^{20}$ and the Danish Hypertension Prevention Project (DHyPP) ${ }^{21}$ studies, candesartan was more effective than placebo in BP reduction.

\section{Combination therapy studies}

The Nifedipine Candesartan Combination (NICE Combi) trial ${ }^{22}$ was a 16-week study of 258 patients with essential hypertension (age range $20-80$ years). The trial investigated the changes in BP, pulse pressure (PP), and urine albumin-to-creatinine ratio (UACR) in these patients randomized to candesartan monotherapy or candesartan plus controlled-release nifedipine. SBP, DBP, and PP were significantly more reduced in the combination therapy group than in the monotherapy group $(P<0.0001$ for SBP and DBP; $P=0.0031$ for PP). UACR decreased significantly in the combination therapy group $(P<0.05)$ but not in the monotherapy group.

Another 16-week study ${ }^{23}$ with the objective of evaluating the efficacy and tolerability of $32 \mathrm{mg}$ candesartan cilexetil in combination with 12.5 or $25 \mathrm{mg}$ hydrochlorothiazide (HCTZ) in patients with hypertension not optimally controlled with candesartan monotherapy reported reduction of BP by $6.1 / 5.6 \mathrm{mmHg}$ in the $32 \mathrm{mg}$ candesartan group (vs $13.0 / 8.8 \mathrm{mmHg}$ in the $32 / 12.5 \mathrm{mg}$ 


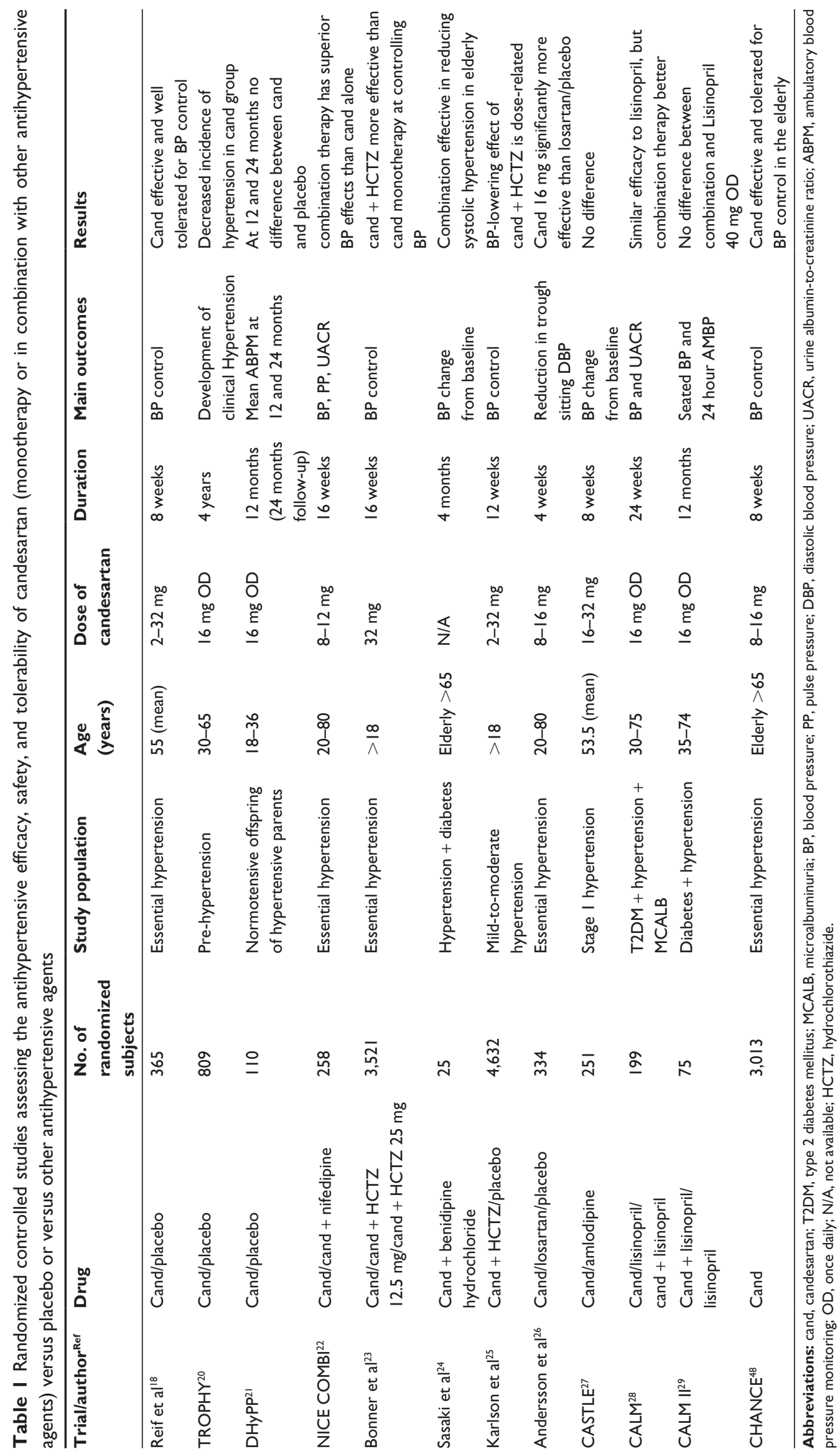




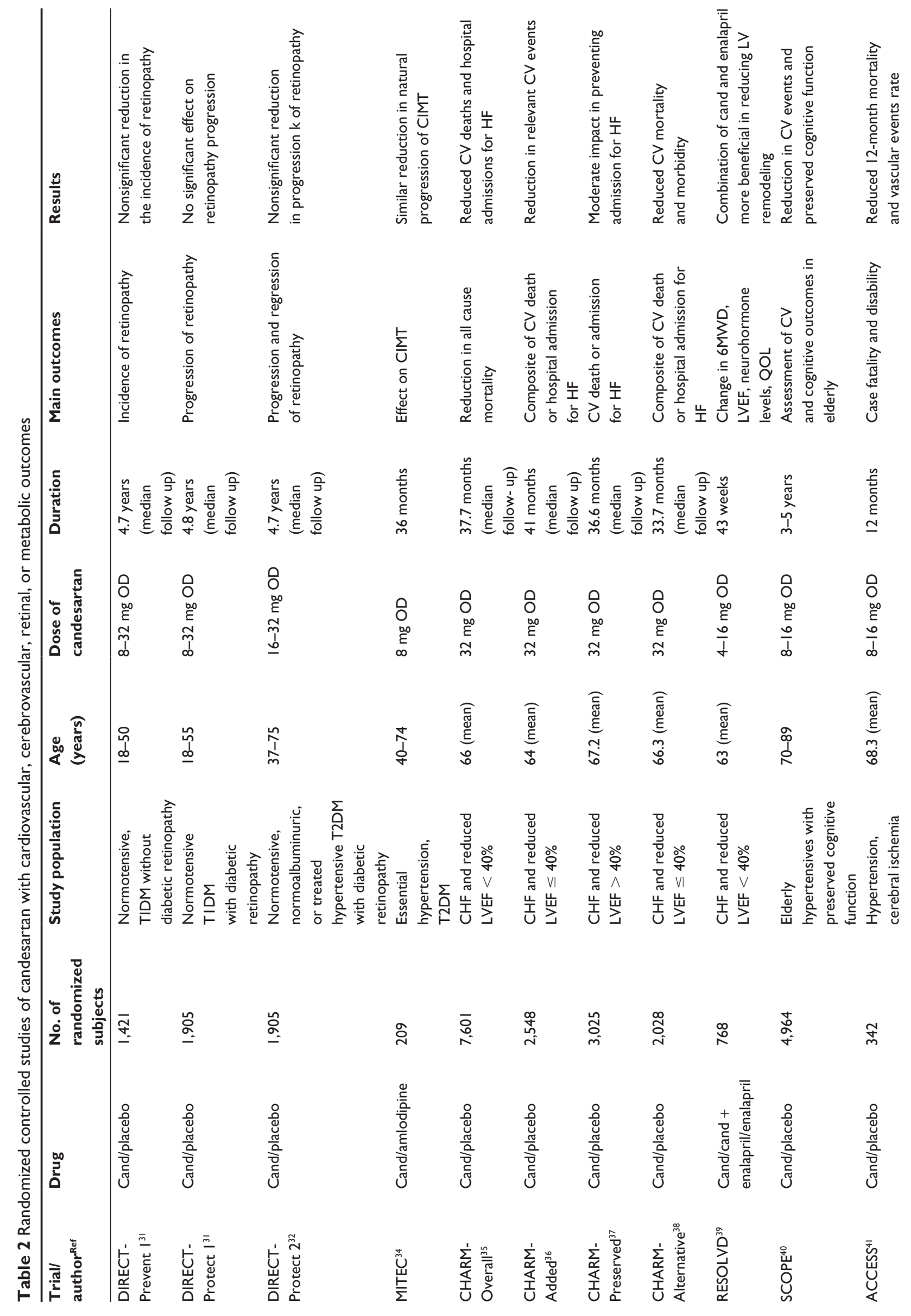



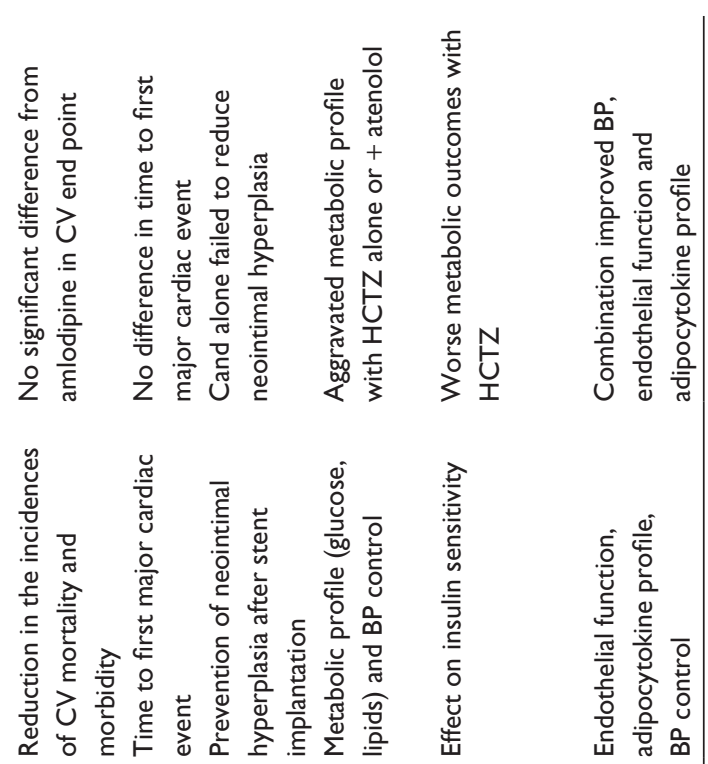

candesartan-HCTZ group and $15.5 / 10.0 \mathrm{mmHg}$ in the $32 / 25 \mathrm{mg}$ candesartan-HCTZ group; $P<0.01$ ). Therefore, candesartan-HCTZ combination was concluded as effective for the treatment of hypertension in patients with hypertension not optimally controlled with candesartan monotherapy. Also, in a smaller study of 25 elderly Japanese hypertensive patients with diabetes who received candesartan and add-on calcium chanel blocker (CCB) treatment benidipine hydrochloride and who were followed up for 4 months, Sasaki et $\mathrm{a}^{24}$ showed significant reduction in SBP and DBP after the addition of benidipine hydrochloride (from 154/91 to 139/78 mmHg; $P<0.01$ ).

A large, randomized, double-blind, placebo-controlled study of 4,632 patients with mild to moderate hypertension used a mathematical model ( $\mathrm{E}_{\max }$ model) to describe the placebo-adjusted dose-response surface for SBP and DBP reductions after $8-12$ weeks of combination therapy with candesartan (2-32 mg) and HCTZ (6.25-25 mg). ${ }^{25}$ Reduction of BP increased with increasing doses of candesartan-HCTZ, from 5.9 to $17.4 \mathrm{mmHg}$ for SBP and from 2.8 to $10.2 \mathrm{mmHg}$ for DBP. Using this model, it was concluded that the effect of combination therapy with candesartan-HCTZ is doserelated over a wide range of doses and that the effects of the components were fully additive.

\section{Comparative efficacy: candesartan versus other antihypertensives}

A multicenter study that compared the antihypertensive effect and tolerability of candesartan cilexetil with those of losartan and placebo in patients with essential hypertension concluded that once-daily dose $16 \mathrm{mg}$ of candesartan cilexetil is significantly more effective than $50 \mathrm{mg}$ of losartan. ${ }^{26}$ In this study, $8 \mathrm{mg}$ of candesartan was as effective as $50 \mathrm{mg}$ of losartan, whereas $16 \mathrm{mg}$ of candesartan cilexetil was significantly more effective $(P=0.013)$. Compared with the placebo treatment, trough sitting DBP was significantly reduced by a mean of $8.9 \mathrm{mmHg}(P<0.001)$ with $8 \mathrm{mg}$ of candesartan cilexetil and $10.3 \mathrm{mmHg}(P<0.001)$ with $16 \mathrm{mg}$ of candesartan cilexetil.

Fabia et $\mathrm{al}^{19}$ conducted a meta-analysis to systematically review the antihypertensive activity of ARBs. In this analysis, 47 patient cohorts received ARB in monotherapy, 10 received placebo, 10 received amlodipine, and 5 received enalapril. The lowering of clinical and ambulatory BP during daytime, nighttime, 24-hour period and the last 4-hour period for each of the drugs considered were calculated and appropriately adjusted for. When only ARBs were evaluated, the drug used was a determinant for SBP reduction, whereas for DBP, the influence was on the $\mathrm{BP}$ reduction and the duration of 
the antihypertensive activity. The dose used had a particular influence on the duration of the antihypertensive activity for both SBP and DBP. Candesartan, telmisartan, irbesartan, and olmesartan all showed similar patterns of SBP and DBP reductions.

The antihypertensive efficacy and tolerability of candesartan and amlodipine were evaluated in an 8-week, multicenter, double-blind, randomized, parallel-group, forced-titration study (a comparative study of Candesartan and Amlodipine for Safety, Tolerability, and Efficacy [CASTLE]). ${ }^{27}$ A total of 251 adult patients with mild hypertension were randomized to receive $16 \mathrm{mg}$ of candesartan or $5 \mathrm{mg}$ of amlodipine once daily (uptitrated to $32 \mathrm{mg}$ of candesartan or $10 \mathrm{mg}$ of amlodipine once daily after 4 weeks). There were no significant differences between the candesartan and the amlodipine regimens in reducing BP as $79 \%$ of patients on candesartan and $87 \%$ of patients on amlodipine were controlled (DBP $<90 \mathrm{mmHg}$ ). The primary end point (change in trough sitting DBP from baseline to week 8) was $-10.2 \mathrm{mmHg}(-11.6$ to $-8.9 \mathrm{mmHg})$ for patients in the candesartan group and $-11.3 \mathrm{mmHg}(-12.6$ to -10.0 $\mathrm{mmHg})$ for patients in the amlodipine group $(P=0.25)$.

\section{Prevention of hypertension}

Several clinical trials, including the TROPHY ${ }^{20}$ and the DHyPP, ${ }^{21}$ have been conducted to evaluate the efficacy of candesartan in preventing the occurrence of clinical hypertension in subjects at risk compared with placebo. The hypothesis was that angiotensin II is a key player in the genesis of hypertension and by blocking the RAAS in patients with high-normal BP or those at risk for hypertension, it would be prevented in the long term.

The TROPHY trial was a 4-year investigator-initiated trial of 809 randomized subjects that examined whether early pharmacological treatment in subjects with "high-normal" BP might prevent or delay the development of clinical hypertension. At year 4, there was a relative reduction in the risk of new-onset hypertension of $15.6 \%$ in participants in the candesartan group $(P=0.007) .{ }^{20}$ The DHyPP study investigated whether early treatment with candesartan in young normotensive offspring of hypertensive parents persistently reduced BP after withdrawal of treatment. After 12 months of therapy, there was reduction in mean ambulatory BP monitoring by $-3.9 /-3.4 \mathrm{mmHg}$ for candesartan versus $0.3 / 0.6 \mathrm{mmHg}$ for placebo $(P<0.0001),{ }^{21}$ but after 12 and 24 months of withdrawal of active treatment, there was no difference. ${ }^{21}$ Overall, although these trials indicate that candesartan can reduce $\mathrm{BP}$ in persons with prehypertension and persons at risk for hypertension, the trials also showed that it does not ultimately prevent hypertension but may only delay its onset.

\section{Candesartan: prevention of target organ damage \\ Microalbuminuria}

The Candesartan and Lisinopril Microalbuminuria (CALM) studies (CALM and CALM II) ${ }^{28,29}$ were designed to assess and compare the effects of candesartan or lisinopril, or both, principally on BP and on urinary albumin excretion (CALM) in patients with microalbuminuria, hypertension, and type 2 diabetes. In the CALM study ${ }^{28}$ after 12 weeks of treatment, both candesartan and lisinopril monotherapies showed equal efficacy in DBP and UACR definition reduction. At 24 weeks of treatment, mean reduction in DBP with dual therapy (16.3, $13.6-18.9 \mathrm{mmHg} ; P<0.001)$ was significantly greater than that with candesartan $(10.4,7.7-13.1 \mathrm{mmHg} ; P<0.001)$ or lisinopril $(10.7,8.0-13.5 \mathrm{mmHg} ; P<0.001)$ alone. Mean UACR reduction at 24 weeks of treatment was also significantly greater with dual therapy than with candesartan or lisinopril alone. The CALM II study ${ }^{29}$ with longer duration of follow-up (12 months) had only $2 \mathrm{arms} \mathrm{(40} \mathrm{mg}$ lisinopril daily and $20 \mathrm{mg}$ lisinopril daily plus $16 \mathrm{mg}$ candesartan daily) and showed no statistically significant difference between lisinopril (40 mg once daily) and lisinopril (20 mg) in combination with candesartan (16 mg once daily) in reducing both SBP and DBP in hypertensive patients with diabetes. Although no significant difference in BP control or reduction in albuminuria was seen in the CALM II study, the investigators suggested that the use of dual blockade would diminish the ACE-escape phenomenon while preserving the effect on bradykinin degradation from the ACE inhibitor.

The ONTARGET study ${ }^{30}$ that tested the dual blockade of the RAAS in patients at high CV risk also reported slightly better control of BP with ARB and an ACE inhibitor in combination, but no improvement in $\mathrm{CV}$ outcome and more adverse events were reported. Progression to microalbuminuria was delayed by combination therapy compared with monotherapy alone, but glomerular filtration rate was lower in the combination group and there were more cases of acute renal failure. Currently, dual blockade with an ACE inhibitor and an ARB is not generally recommended for prevention of microalbuminuria as evidence that dual blockade provides additional benefits for renal and $\mathrm{CV}$ outcomes is lacking.

\section{Diabetic retinopathy}

The DIabetic REtinopathy Candesartan Trials (DIRECT) programme, ${ }^{31,32}$ consisting of 3 separate randomized, double-blind, placebo-controlled clinical trials, was designed to assess whether candesartan could reduce (1) incidence of retinopathy in type 1 diabetes (DIRECT-Prevent 1), ${ }^{31}$ (2) progression of retinopathy 
in type 1 diabetes (DIRECT-Protect 1 ), ${ }^{31}$ and (3) progression of retinopathy in type 2 diabetes (DIRECT-Protect 2) (Table 2) ${ }^{32}$ In the study conducted on patients with type 1 diabetics, incidence of retinopathy was $25 \%$ in the candesartan group versus $31 \%$ in the placebo group $(P=0.0508)$, whereas established retinopathy progressed equally $(13 \%)$ in both groups $(P=0.85) .{ }^{31}$ Although by the end of the trial, the results of DIRECT-Protect 2 showed an overall change toward less severe retinopathy in the candesartan group (odds ratio $=1.17$; 95\% CI, 1.05-1.30, $P=0.003$ ), the risk of progression of retinopathy was nonsignificantly reduced by $13 \%$ in patients on candesartan compared with those on placebo hazard ratio $[\mathrm{HR}]=0.87 ; 95 \% \mathrm{CI}$, $0 \cdot 70-1 \cdot 08, P=0.20){ }^{32}$

The findings of the DIRECT study are in close agreement with the results of the EUrodiab Controlled trial of Lisinopril in Insulin-dependent Diabetes (EUCLID) study ${ }^{33}$ (30\% reduction in incidence of retinopathy), which suggested that blockade of the RAAS with the ACE inhibitor, lisinopril, could reduce both incidence and progression of retinopathy in patients with type 1 diabetes. Therefore, the DIRECT investigators have concluded that candesartan reduces the incidence of retinopathy in patients with type 1 diabetes and have suggested that treatment with candesartan in type 2 diabetic patients with mild to moderate retinopathy could induce improvement of retinopathy.

\section{Carotid intima media thickness}

The Media Intima Thickness Evaluation with Candesartan (MITEC) study $^{34}$ was a multicenter, randomized, doubleblind, active controlled, and parallel-group study conducted in hypertensive patients with type 2 diabetes to evaluate the effect of candesartan in the progression of carotid intima media thickness (CIMT) over 36 months in comparison with amlodipine (Table 2). No significant differences were observed between the two groups for change in the progression of CIMT at 12, 24, and 36 months $(P=0.425, P=0.442$, and $P=0.549$, respectively). At the last visit, CIMT regression was observed in $52.2 \%$ of patients receiving candesartan and in $51.3 \%$ of patients receiving amlodipine $(P=.908)$. The results of this study, therefore, showed that candesartan and amlodipine change the natural progression of CIMT in similar ways in hypertensive patients with type 2 diabetes.

\section{Candesartan: outcome studies}

Several studies have shown that ARBs effectively reduce BP. However, reduction of BP is only a surrogate end point as these studies have also verified the importance of ARBs in protecting target organs. ARBs have shown favorable effects on hemodynamic measurements, neurohumoral activity, and left-ventricular remodeling when added to ACE inhibitors in patients with chronic heart failure (CHF).

The Candesartan in Heart failure: Assessment of Reduction in Mortality and Morbidity (CHARM) programme ${ }^{35-38}$ was specifically designed as three parallel, independent, integrated, randomized, double-blind, placebo-controlled, clinical trials comparing candesartan with placebo in three distinct but complementary populations of patients with symptomatic diastolic HF (CHARM-Preserved) or symptomatic systolic HF (CHARM-Added and CHARMAlternative). In CHARM-Overall ${ }^{35}$ study (primary end point: all-cause mortality), 7,601 patients with $\mathrm{CHF}$ and/or left ventricular ejection fraction $\leq 40$ or $\geq 40$ were randomly assigned to candesartan or placebo therapy group. There were fewer deaths $(23 \%)$ in the candesartan group than in the placebo group $(25 \%)$ (unadjusted $\mathrm{HR}=0.91 ; 95 \% \mathrm{CI}$, $0.83-1.00, P=0.055$ ), with fewer $\mathrm{CV}$ deaths (unadjusted $\mathrm{HR}=0.88 ; 95 \% \mathrm{CI}, 0.79-0.97, P=0.012)$ and hospital admissions for $\mathrm{CHF}(P<0.0001)$ in the candesartan group. In the CHARM-Added study ${ }^{36}(\mathrm{n}=2,548$; primary end point: composite of $\mathrm{CV}$ death or hospital admission for $\mathrm{CHF}$ ), $38 \%$ of patients in the candesartan group and $42 \%$ of patients in the placebo group experienced the primary outcome (unadjusted HR $=0.85 ; 95 \% \mathrm{CI}, 0.75-0.96, P=0.011$ ), and candesartan demonstrated significant reduction of each of the components of the primary outcome, as well as the total number of hospital admissions for $\mathrm{CHF}$. The results of the CHARM-Preserved ${ }^{37}$ study conducted in patients with preserved left ventricular function showed that $\mathrm{CV}$ death did not differ between groups (170 vs 170), but fewer patients in the candesartan group than in the placebo group were admitted one or more times for CHF (230 vs 279; $P=0.017$ ). Similarly, the results of the CHARM-Alternative study ${ }^{38}$ conducted in $\mathrm{CHF}$ patients intolerant of ACE inhibitors showed that fewer patients in the candesartan group had $\mathrm{CV}$ death or hospital admission for CHF (unadjusted HR $=0.77 ; 95 \%$ CI, $0.67-0.89 ; P=0.0004$ ) and that each component of the primary outcome was reduced, as was the total number of hospital admissions for CHF.

Other large trials have also tested the effects of candesartan on CV outcomes in different populations. Some of these studies (Randomized Evaluation of Strategies for Left Ventricular Dysfunction [RESOLVD], Study on COgnition and Prognosis in the Elderly [SCOPE], Acute Candesartan Cilexetil Therapy in Stroke Survivors [ACCESS], Candesartan Antihypertensive Survival Evaluation in Japan [CASE-J], Heart Institute of Japan Candesartan Randomized Trial for 
Evaluation in Coronary Artery Disease [HIJ-CREATE], and the Insight of Stent intimal Hyperplasia Inhibition by New angiotensin II receptor antagonist trial [ISHIN] $]^{39-44}$ have mostly reported favorable results for candesartan when compared with placebo or in combination with another agent, but the studies have found no difference in CV end points in comparison with other antihypertensive agents. For instance, in the RESOLVD pilot study, ${ }^{39}$ end-diastolic (EDV) and end-systolic (ESV) volumes increased less with combination therapy (EDV $8 \pm 4 \mathrm{~mL}$; ESV $1 \pm 4 \mathrm{~mL} ; P<0.01$ ) than with candesartan alone (EDV $27 \pm 4 \mathrm{~mL}$; ESV $18 \pm 3 \mathrm{~mL}$ ) or enalapril alone (EDV $23 \pm 7$ $\mathrm{mL}$; ESV $14 \pm 6 \mathrm{~mL}$ ). However, the CASE-J Trial, ${ }^{42}$ which compared the long-term effects of candesartan and amlodipine on the incidence of $\mathrm{CV}$ events, reported no significant differences in CV morbidity or mortality in high-risk Japanese patients with hypertension $(\mathrm{HR}=1.01 ; 95 \% \mathrm{CI}, 0.79-1.28$, $P=0.969)$. Also, the HIJ-CREATE ${ }^{43}$ study designed to test whether ARB therapy can reduce the incidence of $\mathrm{CV}$ events compared with non-ARB-based standard pharmacotherapy in coronary artery disease patients with hypertension showed no significant differences in first major adverse CV events compared with the non-ARB treatment group: CV death $(2.7 \%$ vs $2.4 \% ; \mathrm{HR}=1.14 ; 95 \% \mathrm{CI}, 0.66-1.95)$, nonfatal myocardial infarction $(2.8 \%$ vs $2.5 \%$; HR $=1.12 ; 95 \% \mathrm{CI}, 0.66-1.88)$, or HF $(3.9 \%$ vs $4.3 \%$; HR $=0.91$; 95\% CI, 0.59-1.40).

The SCOPE ${ }^{40}$ was an international outcomes study conducted between 1997 and 2002 in 527 centers in 15 countries worldwide. The design was a prospective, double-blind, randomized, and parallel-group study, which included 4,964 patients aged 70-89 years with SBP $160-179 \mathrm{mmHg}$ or DBP 90-99 mmHg, or both, and with a mini-mental state evaluation (MMSE) score of at least 24. Patients were randomly assigned to receive $8 \mathrm{mg}$ of candesartan daily or placebo (it was a comparison with a control group that received other antihypertensive drugs, mostly diuretics). Candesartan-based treatment reduced nonfatal stroke by $28 \%$ (relative risk $[\mathrm{RR}]=0.72 ; 95 \% \mathrm{CI}$, $0.53-0.99, P=0.04)$ and all stroke by $24 \%(\mathrm{RR}=0.76 ; 95 \% \mathrm{CI}$, $0.58-1.01, P=0.056)$. The events rate for nonfatal stroke was 7.4 events per 1,000 patient-years compared with 10.3 events per 1,000 patient-years for the candesartan and the placebo group, respectively. The mean change in MMSE score was not significantly different between the treatment groups (candesar$\tan -0.49$ and placebo $-0.64 ; P=0.20$ ), and there was also no significant difference in dementia between the treatment groups (6.8 events per 1,000 patient-years in the candesartan group and 6.3 events per 1,000 patient-years in the control group). Finally, although the use of candesartan in the CHARM-Overall study ${ }^{35}$ did not significantly reduce the risk of stroke (candesartan
141 and placebo 146; $P=0.63$ ), the significant benefits of candesartan treatment were still maintained when a prespecified analysis of time to first event was conducted for nonfatal $\mathrm{CV}$ events, admission to hospital for HF and CV death.

\section{Candesartan: trials with metabolic- profile-based outcomes}

A few trials that have primarily or secondarily assessed the metabolic effects of candesartan include the Antihypertensive Treatment and Lipid Profile in a North of Sweden Efficacy Evaluation (ALPINE) study, ${ }^{45}$ the Mechanisms for the Diabetes Preventing Effect of Candesartan (MEDICA) Study, ${ }^{46}$ the HIJ-CREATE, ${ }^{43}$ and the CASE-J Trial. ${ }^{42}$

Koh et $\mathrm{al}^{47}$ have published the results of a small, randomized, double-blind, placebo-controlled cross-over trial with 3 treatment arms that sought to clarify whether the combination therapy of ramipril and candesartan had additive beneficial effects to simultaneously improve the endothelial dysfunction and the adipocytokine profiles in patients with hypertension. Combination therapy improved these outcome measures to a greater extent than did either ramipril or candesartan alone. In addition, combination therapy reduced plasma leptin levels to a greater extent than did either ramipril or candesartan alone $(P=0.042)$. Change in adiponectin levels showed correlations with: change in the quantitative insulin sensitivity check index [QUICKI] $(\mathrm{r}=0.319, P=0.066)$ following ramipril therapy; change in QUICKI $(\mathrm{r}=0.374, P=0.029)$ following combination therapy; and change in QUICKI ( $\mathrm{r}=0.607, P<$ $0.001)$ following candesartan therapy. QUICKI $(r=0.607$; $P<0.001)$ following candesartan therapy. The result from this trial suggests that candesartan, alone or in combination with ramipril, has vascular benefits by improving endothelial dysfunction commonly observed in diabetes, insulin resistance, and other disease states that may be associated with impaired nitric oxide release from the endothelium. The improvement in endothelial dysfunction is thought to possibly occur by targeting the RAAS through different mechanisms and by body mass index independent increases in adiponectin levels and insulin sensitivity.

The aim of the ALPINE study ${ }^{45}$ was to compare the long-term effect of low-dose HCTZ, alone or in combination with atenolol (a $\beta$-blocker), with that of candesartan, alone or in combination with felodipine (a CCB), in newly diagnosed patients with primary hypertension. The objectives included comparisons of the effects on glucose and lipoprotein metabolism. Fasting serum insulin and fasting plasma glucose levels increased in the HCTZ group compared with unaffected levels in the candesartan group. Diabetes mellitus 
was diagnosed in $4.1 \%$ of the HCTZ group (vs $0.5 \%$ in the candesartan group; $P=0.030$ ). The HCTZ group also had higher mean triglyceride with lower mean high-density lipoprotein-cholesterol than the candesartan group. At 12 months, 18 patients in the HCTZ group (vs 5 patients in the candesartan group, $P=0.007$ ) had a metabolic syndrome, as defined by the World Health Organization.

The favorable metabolic outcomes obtained from other studies can be summarized as follows: in the CASE-J study, ${ }^{42}$ new-onset diabetes occurred in significantly fewer patients treated with candesartan-based regimens than in those treated with amlodipine-based regimens; in the HIJ-CREATE study, ${ }^{43}$ new-onset diabetes was diagnosed in fewer of the patients assigned to the candesartan-group compared with the controls $(\mathrm{HR}=0.37 ; 95 \% \mathrm{CI}, 0.16-0.89 ; P=0.03)$; in the MEDICA study, ${ }^{46}$ visceral fat redistribution, liver fat accumulation, low-grade inflammation, and aggravated insulin resistance were demonstrated after HCTZ treatment but not after candesartan treatment.

\section{Candesartan: safety, tolerability, and patient perspectives}

Most of the reported trials have included and assessed the safety, tolerability, and occurrence of adverse events associated with candesartan. In general, candesartan has been reported by these trials to be safe and well tolerated by patients and significantly fewer patients have usually discontinued their participation or withdrawn from most trials due to adverse events or for safety concerns.

In the CHANCE study, ${ }^{48}$ once-daily dose of $8-16 \mathrm{mg}$ of candesartan was effective and well tolerated in the management of arterial hypertension in elderly subjects. In the MITEC study, ${ }^{34}$ significantly more adverse events related to the study drug occurred in the amlodipine group than in the candesartan group $(32.1 \%$ vs $13.0 \% ; P=0.001)$. In the HIJ-CREATE study, ${ }^{43}$ the difference in adverse events was found to be driven by cough and anemia in the non-ARB group leading to more frequent discontinuation of the study drug in the non-ARB-based standard therapy group than in the candesartan group $(12.2 \%$ vs $5.7 \% ; P<0.001)$.

However, in the CHARM study, ${ }^{35}$ even though candesartan was well tolerated by patients, it was associated with a greater occurrence of discontinuation of the study drug than placebo due to hypotension, hyperkalemia, and increase in serum creatinine levels. Also, more cancer deaths occurred in the candesartan group, but these deaths were attributed to the play of chance since the investigator-reported rate of nonfatal neoplasms did not differ among treatment groups. No other studies have reported such findings. In all, candesartan appears to be safe and well-tolerated drug.

\section{Conclusions}

Candesartan, a long-acting antihypertensive agent, has been shown to have a more efficacious antihypertensive activity than other ARBs such as losartan, and it effectively combines with other antihypertensive agents such as thiazide diuretics and CCBs to control BP. Several randomized clinical studies have also shown candesartan to be a welltolerated drug with favorable metabolic characteristics. It reduces microalbuminuria in type 2 diabetics, prevents progression of CIMT, and may have positive benefits in preventing type 2 diabetic retinopathy. Candesartan reduces $\mathrm{CV}$ events in patients with $\mathrm{HF}$ intolerant to ACE inhibitors and in combination with ACE inhibitors in patients with HF and reduced ejection fraction. There are suggestive data that it may be useful in patients with acute stroke and prevent stroke in elderly hypertensives. Candesartan is, therefore, an attractive antihypertensive agent with additional benefits on target organ damage and both $\mathrm{CV}$ and cerebrovascular outcomes.

\section{Disclosures}

The authors report no conflicts of interest in this work.

\section{References}

1. Kearney PM, Whelton M, Reynolds K, Muntner P, Whelton PK, He J. Global burden of hypertension: analysis of worldwide data. Lancet. 2005;365:217-223.

2. Wolf-Maier K, Cooper RS, Banegas JR, et al. Hypertension prevalence and blood pressure levels in 6 European countries, Canada and the United States. JAMA. 2003;289:2363-2369.

3. Kearney PM, Whelton M, Reynolds K, Whelton PK, He J. Worldwide prevalence of hypertension: a systematic review. J Hypertens. 2004;22:11-19.

4. Marques-Vidal P, Arveiler D, Amouyel P, Bingham A, Ferrières J. Sex differences in awareness and control of hypertension in France. J Hypertens. 1997; 15:1205-1210.

5. Burt VL, Whelton P, Roccella EJ, et al. Prevalence of hypertension in the US adult population: results from the third National Health and Nutrition Examination Survey, 1988-1991. Hypertension. 1995;25:305-313.

6. De Henauw S, De Bacquer D, Fonteyne W, Stam M, Kornitzer M, De Backer G. Trends in the prevalence, detection, treatment and control of arterial hypertension in the Belgian adult population. J Hypertens. 1998; 16:277-284

7. Psaltopoulou T, Orfanos P, NaskaA, Lenas D, Trichopoulos D, TrichopoulouA. Prevalence, awareness, treatment and control of hypertension in a general population sample of 26,913 adults in the GreekEPIC study. Int JEpidemiol. 2004;33: 1345-1352.

8. Asmar R, Vol S, Pannier B, Brisac AM, Tichet J, El Hasnaoui A. High blood pressure and associated cardiovascular risk factors in France. J Hypertens. 2001;19: 1727-1732.

9. Guidelines Committee. European Society of Hypertension - European Society of Cardiology guidelines for the management of arterial hypertension. J Hypertens. 2003;21:1011-1053. 
10. Lewington S, Clarke R, Qizilbash N, Peto R, Collins R; Prospective Studies Collaboration. Age-specific relevance of usual blood pressure to vascular mortality: a metaanalysis of individual data for one million adults in 61 prospective studies. Lancet. 2002;360:1903-1913.

11. Mancia G, De Backer G, Dominiczak A, et al. 2007 Guidelines for the Management of Arterial Hypertension: the Task Force for the Management of Arterial Hypertension of the European Society of Hypertension (ESH) and of the European Society of Cardiology (ESC). J Hypertens. 2007;25:1105-1187.

12. Hyman DJ, Pavlik VN. Characteristics of patients with uncontrolled hypertension in the United States. $N$ Engl J Med. 2001;345:479-486.

13. Morimoto S, Ogihara T. TCV-116: a new angiotensin II type-1 receptor antagonist. Cardiovasc Drug Rev. 1994;12:153-164.

14. Hübner R, Högemann AM, Sunzel M, Riddell JG. Pharmacokinetics of candesartan after single and repeated doses of candesartan cilexetil in young and elderly healthy volunteers. J Hum Hypertens. 1997;11 Supp12: S19-S25.

15. Ojima M, Inada Y, Shibouta Y, et al. Candesartan (CV-11974) dissociates slowly from the angiotensin AT1 receptor. Eur J Pharmacol. 1997;319:137-146.

16. Noda $M$, Shibouta $Y$, Inada $Y$, et al. Inhibition of rabbit aortic angiotensin II (AII) receptor by CV-11974, a new nonpeptide AII antagonist. Biochem Pharmacol. 1993;46:311-318.

17. Elmfeldt D, George M, Hubner R, Olofsson B. Candesartan cilexetil, a new generation angiotensin II antagonist, provides dose dependent antihypertensive effect. J Hum Hypertens. 1997;11 Suppl 2:S49-S53.

18. Reif M, White WB, Fagan TC, et al; for the Candesartan Cilexetil Study Investigators. Effects of candesartan cilexetil in patients with systemic hypertension. Am J Cardiol. 1998;82:961-965.

19. Fabia MJ, Abdilla N, Oltra R, Fernandez C, Redon J. Antihypertensive activity of angiotensin II AT1 receptor antagonists: a systematic review of studies with $24 \mathrm{~h}$ ambulatory blood pressure monitoring. J Hypertens. 2007; 25:1327-1336.

20. Julius S, Nesbitt SD, Egan BM, et al; for the Trial of Preventing Hypertension (TROPHY) Study Investigators. Feasibility of treating prehypertension with an angiotensin-receptor blocker. $N$ Engl J Med. 2006;354:1685-1697.

21. SkovK, EiskjærH, Hansen HE, Madsen JK, KvistS, Mulvany MJ.Treatment of young subjects at high familial risk of future hypertension with an angiotensin-receptor blocker. Hypertension. 2007;50:89-95.

22. Hasebea N, Kikuchia K; for the NICE Combi Study Group. Controlled-release nifedipine and candesartan low-dose combination therapy in patients with essential hypertension: the NICE COMBI (Nifedipine and Candesartan Combination) Study. J Hypertens. 2005;23:445-453.

23. Bonner G, Calder B, Dzyak G, et al. Antihypertensive efficacy and tolerability of candesartan-hydrochlorothiazide $32 / 12.5 \mathrm{mg}$ and $32 / 25 \mathrm{mg}$ in patients not optimally controlled with candesartan monotherapy. Blood Press. 2008;17 Suppl 2:S22-30.

24. Sasaki H, Kanai S, Oyama T, Miyashita Y, Yamamura S, Shirai K. Effect of combination therapy of benidipine hydrochloride and candesartan cilexetil on serum lipid metabolism and blood pressure in elderly hypertensive patients with type 2 diabetes mellitus. J Atheroscler Thromb. 2006;13:149-157.

25. Karlson BW, Zetterstrand S, Olofsson B, Elmfeldt D. A dose-response analysis of candesartan-hydrochlorothiazide combination therapy in patients with hypertension. Blood Press. 2009;18:149-156.

26. Andersson OK, Neldam $\mathrm{S}$. The antihypertensive effect and tolerability of candesartan cilexetil, a new generation angiotensin II antagonist, in comparison with losartan. Blood Press. 1998;7:53-59.

27. Kloner RA, Weinberger M, Pool JL, et al; for the Comparison of Candesartan and Amlodipine for Safety, Tolerability and Efficacy (CASTLE) Study Investigators. Comparative effects of candesartan cilexetil and amlodipine in patients with mild systemic hypertension. Am J Cardiol. 2001;87:727-731.
28. Mogensen CE, Neldam S, Tikkanen I, et al; for the CALM Study Group. Randomised controlled trial of dual blockade of reninangiotensin system in patients with hypertension, microalbuminuria, and noninsulin dependent diabetes: the Candesartan and Lisinopril Microalbuminuria (CALM) Study. BMJ. 2000;321:1440-1444.

29. Andersen NH, Poulsen PL, Knudsen ST, et al. Long-term dual blockade with candesartan and lisinopril in hypertensive patients with diabetes. The CALM II study. Diabetes Care. 2005;28:273-277.

30. The ONTARGET Investigators. Telmisartan, ramipril, or both in patients at high risk for vascular events. $N$ Engl J Med. 2008;358: $1547-1559$.

31. Chaturvedi N, Porta M, Klein R, et al; for the DIRECT Programme Study Group. Effect of candesartan on prevention (DIRECT-Prevent 1) and progression (DIRECT-Protect 1) of retinopathy in type 1 diabetes: randomised, placebo-controlled trials. Lancet. 2008;372:1394-1402.

32. Sjølie AK, Klein R, Porta M, et al; for the DIRECT Programme Study Group. Effect of candesartan on progression and regression of retinopathy in type 2 diabetes (DIRECT-Protect 2): a randomised placebo-controlled trial. Lancet. 2008;372:1385-1393.

33. Chaturvedi N, Sjolie AK, Stephenson JM, et al. Effect of lisinopril on progression of retinopathy in normotensive people with type 1 diabetes. The EUCLID Study Group. EURODIAB controlled trial of lisinopril in insulin-dependent diabetes mellitus. Lancet. 1998;351:28-31.

34. Baguet JP, Asmar R, Valensi P, Nisse-Durgeat S, Mallion JM. Effects of candesartan cilexetil on carotid remodeling in hypertensive diabetic patients; the MITEC study. Vasc Heslth Risk Martag. 2009;5:175-183.

35. Pfeffer MA, Swedberg K, Granger CB, et al; for the CHARM Investigators and Committees. Effects of candesartan on mortality and morbidity in patients with chronic heart failure: the CHARM-Overall programme. Lancet. 2003;362:759-766.

36. McMurray JJV, Östergren J, Swedberg K, et al; for the CHARM Investigators and Committees. Effects of candesartan in patients with chronic heart failure and reduced left-ventricular systolic function taking angiotensin converting enzyme inhibitors: the CHARM-Added trial. Lancet. 2003;362:767-771.

37. Yusuf S, Pfeffer MA, Swedberg K, et al; for the CHARM Investigators and Committees. Effects of candesartan in patients with chronic heart failure and preserved left-ventricular ejection fraction: the CHARMPreserved Trial. Lancet. 2003;362:777-781.

38. Granger CB, McMurray JJV, Yusuf S, et al; for the CHARM Investigators and Committees. Effects of candesartan in patients with chronic heart failure and reduced left-ventricular systolic function intolerant to angiotensin-converting-enzyme inhibitors: the CHARM-Alternative trial. Lancet. 2003;362:772-776.

39. McKelvie RS, Yusuf S, Pericak D, et al. Comparison of candesartan, enalapril, and their combination in congestive heart failure Randomized Evaluation of Strategies for Left Ventricular Dysfunction (RESOLVD) Pilot Study. The RESOLVD Pilot Study Investigators. Circulation. 1999;100:1056-1064.

40. Lithell H, Hansson L, Skoog I, et al; for the SCOPE Study Group. The Study on COgnition and Prognosis in the Elderly (SCOPE). Principal results of a randomised double-blind intervention trial. $J$ Hypertens. 2003;21:875-886.

41. Schrader J, Lüders S, Kulschewski A, et al; for the ACCESS Study Group. The ACCESS study evaluation of acute candesartan cilexetil therapy in stroke survivors. Stroke. 2003;34:1699-1703.

42. Ogihara T, Nakao K, Fukui T, et al; for the Candesartan Antihypertensive Survival Evaluation in Japan Trial Group. Effects of candesartan compared with amlodipine in hypertensive patients with high cardiovascular risks. Candesartan Antihypertensive Survival Evaluation in Japan Trial. Hypertension. 2008;51:393-398.

43. Kasanuki H, Hagiwara N, Hosoda S, et al; for the HIJ-CREATE Investigators. Angiotensin II receptor blocker-based vs. non-angiotensin II receptor blocker-based therapy in patients with angiographically documented coronary artery disease and hypertension: the Heart Institute of Japan Candesartan Randomized Trial for Evaluation in Coronary Artery Disease (HIJ-CREATE). Eur Heart J. 2009;30:1203-1212. 
44. Wakeyama T, Ogawa $H$, Iida $H$, et al. Effects of candesartan and probucol on restenosis after coronary stenting results of insight of stent intimal hyperplasia inhibition by new angiotensin ii receptor antagonist (ISHIN) trial. Circ J. 2003;67:519-524.

45. Lindholm LH, Persson M, Alaupovic P, Carlberg B, Svensson A, Samuelsson O. Metabolic outcome during 1 year in newly detected hypertensives: results of the Antihypertensive Treatment and Lipid Profile in a North of Sweden Efficacy Evaluation (ALPINE study). J Hypertens. 2003;21:1563-1574.

46. Eriksson JW, Jansson P, Carlberg B, et al. Hydrochlorothiazide, but not candesartan, aggravates insulin resistance and causes visceral and hepatic fat accumulation. The Mechanisms for the Diabetes Preventing Effect of Candesartan (MEDICA) Study. Hypertension. 2008;52: 1030-1037.
47. Koh KK, Quon MJ, Lee Y, et al. Additive beneficial cardiovascular and metabolic effects of combination therapy with ramipril and candesartan in hypertensive patients. Eur Heart J. 2007;28:1440-1447.

48. Asmar R, Nisse-Durgeat S. A large scale study of angiotensin II inhibition therapy in an elderly population: the CHANCE study. Vasc Health Risk Manag. 2006;2(3):317-323.

\section{Publish your work in this journal}

Integrated Blood Pressure Control is an international, peer-reviewed open-access journal focusing on the integrated approach to managing hypertension and risk reduction. Treating the patient and comorbidities together with diet and lifestyle modification and optimizing healthcare resources through a multidisciplinary team approach constitute key features of the journal. This journal is indexed on American Chemical Society's Chemical Abstracts Service (CAS). The manuscript management system is completely online and includes a very quick and fair peerreview system, which is all easy to use. Visit http://www.dovepress.com/ testimonials.php to read real quotes from published authors.

Submit your manuscript here: http://www.dovepress.com/integrated-blood-pressure-control-journal 